\title{
Radiotherapy side effects: integrating a survivorship clinical lens to better serve patients
}

\author{
V. Dilalla MD CM, ${ }^{* a}$ G. Chaput BA MD MA CAC(Pall Med), ${ }^{\text {ta }}$ T. Williams, ${ }^{\ddagger}$ and K. Sultanem MD ${ }^{\S}$
}

\begin{abstract}
The Canadian Cancer Society estimated that 220,400 new cases of cancer would be diagnosed in 2019. Of the affected patients, more than $60 \%$ will survive for 5 years or longer after their cancer diagnosis. Furthermore, nearly $40 \%$ will receive at least 1 course of radiotherapy (RT). Radiotherapy is used with both curative and palliative intent: to treat early-stage or locally advanced tumours (curative) and for symptom management in advanced disease (palliative). It can be delivered systemically (external-beam RT) or internally (brachytherapy).

Although technique improvements have drastically reduced the occurrence of RT-related toxicity, most patients still experience burdensome RT side effects (sEFFs). Radiotherapy sEFFs are local or locoregional, and manifest in tissues or organs that were irradiated. Side effects manifesting within weeks after RT completion are termed "early sEFFs," and those occurring months or years after treatment are termed "late sEFFs."

In addition to radiation oncologists, general practitioners in oncology and primary care providers are involved in survivorship care and management of RT SEFFs. Here, we present an overview of common sEFFs and their respective management: anxiety, depression, fatigue, and effects related to the head-and-neck, thoracic, and pelvic treatment sites.
\end{abstract}

Key Words Survivorship, radiotherapy, side effects, general practitioners in oncology, primary care providers

Curr Oncol. 2020 April:27(2)107-112 www.current-oncology.com

\section{INTRODUCTION}

The Canadian Cancer Society estimated that 220,400 new cases of cancer would be diagnosed in 2019. Of the affected patients, more than $60 \%$ will survive for 5 years or longer after their cancer diagnosis ${ }^{1}$. Furthermore, nearly $40 \%$ of cancer patients receive at least 1 course of radiotherapy $(\mathrm{RT})^{2}$. Radiotherapy is used with both curative and palliative intent: to treat early-stage or locally advanced tumours (curative) and for symptom management in advanced disease (palliative).

Although technique improvements have drastically reduced RT-related toxicity ${ }^{3}$, most patients still experience burdensome RT side effects (sEFFs) ${ }^{4}$. Radiotherapy sEFFs are local or locoregional, and manifest in tissues or organs that were irradiated. Side effects manifesting during or within weeks after RT completion are termed "early sEFFs," and those occurring months or years after treatment are termed "late sEFFs"4.

In addition to radiation oncologists, general practitioners in oncology and primary care providers are involved in survivorship care ${ }^{5}$, including the management of
RT-induced sEFFs. Here, we present an overview of common sEFFs and their respective management: anxiety, depression, fatigue, and effects related to the head-and-neck (HN), thoracic, and pelvic treatment sites.

\section{SIDE EFFECTS AND THEIR MANAGEMENT}

\section{Distress, Anxiety, and Depression}

Studies have shown an increase in distress, anxiety, and depression in patients undergoing radiation ${ }^{6,7}$. Although such problems tend to decrease upon RT completion, a significant number of patients still manifest psychological

\footnotetext{
These authors share first authorship.
}

This series is brought to you in partnership with the Canadian Association of General Practitioners in Oncology.

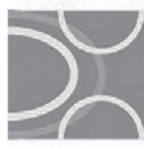


effects after treatment ${ }^{7}$. Patients with pancreatic cancer and lung cancer appear particularly vulnerable, higher rates of depression being associated with those diagnoses $^{8}$. Radiotherapy-induced hypothyroidism, especially in patients with HN cancer, and secondary vitamin $\mathrm{B}_{12}$ malabsorption can contribute to psychological findings and should be ruled out ${ }^{8}$.

Regardless of stage of diagnosis or treatment intent, depression and anxiety affect approximately $20 \%$ and $10 \%$ of patients respectively ${ }^{9}$, but underrepresentation is a concern, given the lack of standardized distress screening programs across Canada ${ }^{10}$. Current guidelines therefore recommend that all patients be screened for distress at their initial post-treatment visit and at regular intervals thereafter, using validated tools such as the revised Edmonton Symptom Assessment System, the Distress Thermometer, or the Patient Health Questionnaire- $2^{10}$. Screening should include an assessment of psychosocial needs and fear of recurrence, with referrals to appropriate resources being promptly made as required ${ }^{10}$. In patients diagnosed with depression, a multidisciplinary approach including both nonpharmacologic and pharmacologic interventions is encouraged ${ }^{11}$.

\section{Fatigue}

Cancer-related fatigue is defined as "a distressing, persistent, subjective sense of physical, emotional, and/or cognitive tiredness or exhaustion related to cancer and/ or cancer treatment that is not proportional to recent activity and interferes with usual functioning" 12 .

Patients often describe fatigue as one of the most distressing adverse effects of treatment ${ }^{12}$. Regardless of treatment site, RT has been reported to cause acute fatigue in up to $80 \%$ of patients, and chronic fatigue can persist in up to $30 \%$ for months to years after treatment ${ }^{13}$. The cause for persistent fatigue is likely multifactorial, but it has been suggested potentially to be secondary to persistent immune system activation or to late effects on major organ systems ${ }^{14}$. Guidelines recommend screening for cancerrelated fatigue in all patients and taking prompt action for potential contributing factors such as anemia, pain, and cardiac or endocrine dysfunction ${ }^{12}$. Nonpharmacologic and pharmacologic treatments might aid in the management of cancer-related fatigue (Table I).

\section{Effects of HN RT}

Approximately $80 \%$ of patients with HN cancer will receive at least 1 course of RT as part of their treatment ${ }^{20}$. A frequent early SEFF of HN RT is oral mucositis: acute inflammation or ulceration, or both, of the oral or oropharyngeal mucosal membranes. Oral mucositis can cause pain and negatively affect capacity to swallow, eat, and speak, which can be very distressing to patients ${ }^{21}$. Oral mucositis is graded on a scale of 1-4 based on severity; Table II summarizes its management ${ }^{22}$.

Other common sEFFs of HN RT include alterations of taste, dysphagia, xerostomia, and hypothyroidism. The latter condition should be recognized because thyroid hormone can readily be replaced. Screening for thyroid dysfunction based on thyroid stimulating hormone levels should be performed every 6-12 months after $\mathrm{RT}^{23}$.
TABLE I Management strategies for cancer-related fatigue

\begin{tabular}{|c|c|}
\hline Strategy & Application \\
\hline Nonpharmacologic & $\begin{array}{l}\text { - Physical exercise }{ }^{12,15} \\
\text { - Yoga }{ }^{16,17} \\
\text { - Cognitive behavioural therapy, } \\
\text { mindfulness-based stress reduction } \\
\text { techniques, educational therapies, } \\
\text { supportive expressive therapies }^{12,18} \\
\text { - } \text { Acupuncture }^{19}\end{array}$ \\
\hline Pharmacologic & $\begin{array}{l}\text { - Methylphenidate for fatigue that } \\
\text { is refractory to nonpharmacologic } \\
\text { interventions }{ }^{12} \\
\text { - Modafinil not recommended }{ }^{12}\end{array}$ \\
\hline
\end{tabular}

Alterations of taste occur in more than $70 \%$ of patients ${ }^{24}$. Taste dysfunction can be partial or complete, and typically occurs 4-5 weeks after RT start ${ }^{25}$. Taste recovery can occur as early as 1 month after RT, and most survivors experience a complete return of taste $6-12$ months after $\mathrm{RT}^{26}$.

The risk of dysphagia in patients with HN cancer who receive RT is high, and its occurrence can negatively affect quality of life ${ }^{27}$. Radiotherapy-induced fibrosis can impair the swallowing musculature ${ }^{28}$ and could lead to nutritional intake through enteral feeding. Radiotherapyinduced fibrosis is dose- and site-dependent ${ }^{28}$, and concomitant chemotherapy can further affect swallowing ${ }^{29}$. The mainstay of management is behavioural swallowing interventions with exercise aids provided by speech-language pathologists ${ }^{30}$. Thus, early referral to a speech-language pathologist is warranted; interventions can be performed to prevent dysphagia onset (before or during treatment) or to minimize existing dysphagia (after treatment $)^{31}$. For persistent and debilitating dysphagia, referral to an experienced gastroenterologist for endoscopic dilatation might be beneficial ${ }^{31}$.

Lastly, xerostomia results from salivary gland dysfunction causing hyposalivation and is associated with swallowing, speech, and oral health problems ${ }^{20}$. Despite technique advancements such as intensity-modulated RT, approximately $40 \%$ of patients still experience burdensome xerostomia ${ }^{20}$. Increasing existing salivary flow (or replacing lost salivary secretions) and maintaining oral health (including treating dental caries and possible infections) are the mainstays of management ${ }^{32}$. After RT, dental visits are recommended at least once every 6 months ${ }^{23}$. Treatment options depend on the presence or absence of residual gland function. If gland function remains, mechanical gland stimulation with sugar-containing gums or xylitol- or sorbitol-containing candy can be attempted ${ }^{32,33}$. Salivary flow can also be stimulated by cholinergic medications such as pilocarpine at a recommended dose of $5 \mathrm{mg} 3$ times daily $^{32,33}$. In the absence of gland function or upon saliva stimulation failure, mouthwashes and saliva substitutes can be used ${ }^{33}$

Notably, HN RT is also associated with other late sEFFs, including lymphedema and carotid artery stenosis (CAS). Lymphedema presents as local swelling because of damage to the lymphatic system, which can affect swallowing, speaking, and body image. Lymphedema management 


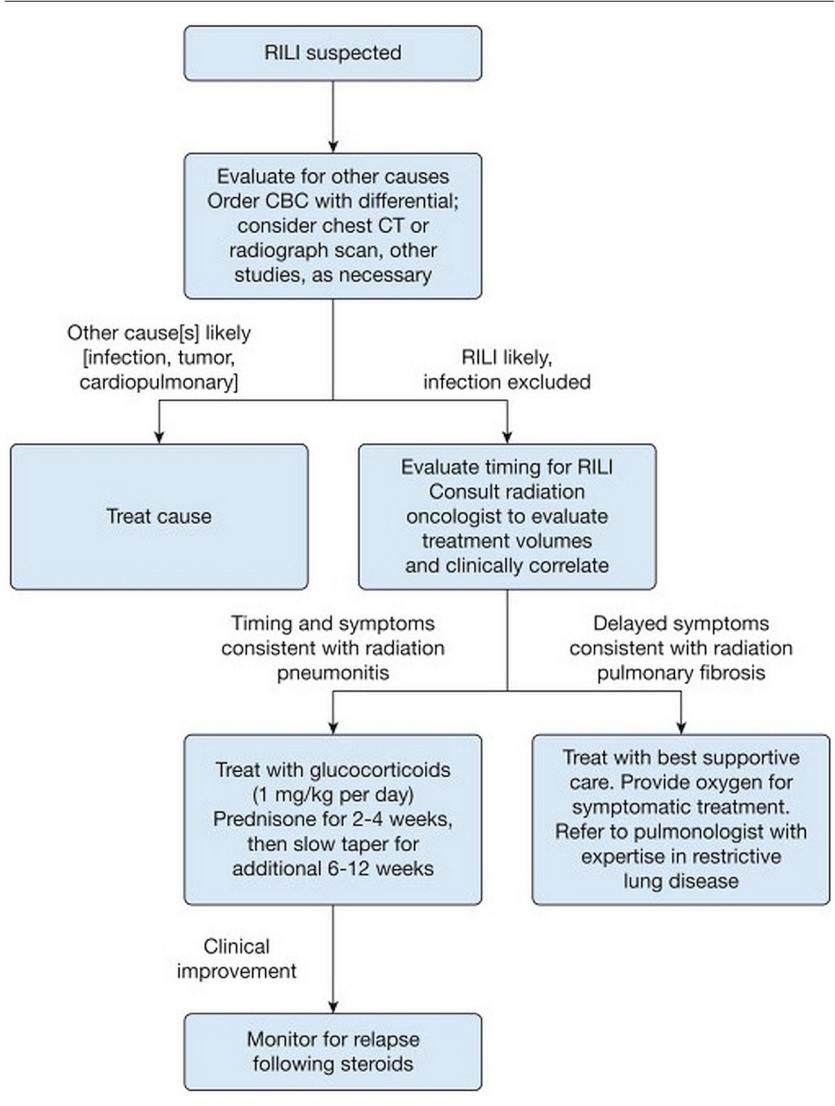

FIGURE 1 Clinical algorithm for the assessment and management of radiation-induced lung injury (RILI). Suspicion of RILI should be raised when a patient's physical examination findings correlate temporally (typically within 3 months) with completion of thoracic radiation. $\mathrm{CBC}=$ complete blood count; $\mathrm{CT}=$ computed tomography. Reprinted with permission (Elsevier) from Hanania et al. ${ }^{35}$.

\section{Effects of Pelvic RT}

Compared with other cancer sites, pelvic cancers more frequently involve treatment with RT. Pelvic RT can lead to gastrointestinal toxicity, sexual dysfunction, and fertility concerns.

Pelvic radiation disease (PRD) is defined as mild-tosevere transient or long-term gastrointestinal symptoms secondary to RT of a pelvic tumour. Patients have reported PRD to have the greatest adverse effect on their quality of life $\mathrm{e}^{42}$. Patients can present with up to 22 gastrointestinal symptoms, and given that each symptom can have more than one cause, symptoms should be investigated systematically ${ }^{4}$. Frequent sEFFs of pelvic RT are diarrhea, rectal bleeding, urgency, and fecal incontinence, all reported in up to $50 \%$ of patients ${ }^{42,44}$. In addition to pelvic RT, patientrelated risk factors for PRD include diabetes, inflammatory bowel disease, collagen vascular disease, low body mass index, and smoking ${ }^{45}$. Table III summarizes the proposed work-up and management for gastrointestinal symptoms linked to PRD. Other pharmacologic (aminosalicylates, sucralfate, amifostine, corticosteroid enemas, bile acid sequestrants, famotidine, and selenium) and nonpharmacologic interventions (dietary modifications, green tea tablets, glutamine) currently have lower-certainty evidence of potential benefit ${ }^{46}$.

Sexual dysfunction after pelvic RT is typically multifactorial and negatively affects patients ${ }^{47}$. In men, erectile dysfunction is a common late sEFF, being reported in up to $50 \%$ of patients at 5 years after $\mathrm{RT}^{48}$. Bladder and bowel dysfunction can also occur and lead to decreased intimacy and self-esteem ${ }^{49}$. Phosphodiesterase type 5 inhibitors, such as sildenafil and tadalafil, have been described as effective to treat RT-associated erectile dysfunction and should be considered for first-line treatment ${ }^{47,49,50}$. In women, sEFFs related to pelvic RT include vaginal dryness

TABLE III Common gastrointestinal symptoms and management ${ }^{\mathrm{a}}$

\begin{tabular}{|c|c|c|c|c|}
\hline Symptom & Investigations & Potential results & Management & Alternative diagnoses \\
\hline Rectal bleeding & $\begin{array}{l}\text { Complete blood count, } \\
\text { coagulation profile, referral } \\
\text { for flexible sigmoidoscopy }\end{array}$ & $\begin{array}{l}\text { Radiation proctopathy } \\
\text { with bleeding from } \\
\text { telangiectasia }\end{array}$ & $\begin{array}{l}\text { Optimize bowel function } \\
\text { and stool consistency } \\
\text { Consider referral to a specialist } \\
\text { for telangiectasia ablation if } \\
\text { affecting quality of life }\end{array}$ & $\begin{array}{l}\text { Hemorrhoids, primary } \\
\text { inflammatory bowel } \\
\text { disease, diverticular } \\
\text { bleeding, new neoplasm }\end{array}$ \\
\hline $\begin{array}{l}\text { Bloating or } \\
\text { abdominal } \\
\text { cramps }\end{array}$ & $\begin{array}{l}\text { Dietary history with } \\
\text { or without test for } \\
\text { carbohydrate malabsorption } \\
\text { with or without biliary } \\
\text { tree ultrasonography }\end{array}$ & $\begin{array}{c}\text { Carbohydrate intolerance, } \\
\text { irritable bowel disease, } \\
\text { gallstones }\end{array}$ & $\begin{array}{l}\text { Treat underlying } \\
\text { Referral to a gastroenterologist } \\
\text { as clinically appropriate }\end{array}$ & Tumour recurrence \\
\hline Diarrhea & $\begin{array}{l}\text { Dietary and lifestyle } \\
\text { assessment, medication } \\
\text { review, referral for } \\
\text { flexible sigmoidoscopy }\end{array}$ & $\begin{array}{l}\text { Radiation proctopathy } \\
\text { or colopathy and pelvic } \\
\text { floor dysfunction }\end{array}$ & $\begin{array}{l}\text { Antidiarrheals, stool bulking } \\
\text { agents, pelvic floor and } \\
\text { toileting exercises }\end{array}$ & $\begin{array}{l}\text { Infectious causes, celiac } \\
\text { disease, dietary causes, } \\
\text { drug-induced causes }\end{array}$ \\
\hline $\begin{array}{l}\text { Fecal } \\
\quad \text { incontinence }\end{array}$ & $\begin{array}{l}\text { Rectal exam, referral for } \\
\text { flexible sigmoidoscopy }\end{array}$ & $\begin{array}{l}\text { Pelvic floor dysfunction } \\
\text { with radiation } \\
\text { proctopathy and fecal } \\
\text { incontinence or leakage }\end{array}$ & $\begin{array}{l}\text { Pelvic floor strengthening } \\
\text { exercises, stool bulking agents, } \\
\text { consider referral to specialist } \\
\text { for sphincter repair }\end{array}$ & $\begin{array}{l}\text { Constipation with overflow } \\
\text { diarrhea, previous sphincter } \\
\text { surgery, childbirth }\end{array}$ \\
\hline Tenesmus & $\begin{array}{l}\text { Referral for flexible } \\
\text { sigmoidoscopy }\end{array}$ & Radiation proctopathy & $\begin{array}{l}\text { Pelvic floor strengthening } \\
\text { exercises, stool bulking agents }\end{array}$ & $\begin{array}{l}\text { New neoplasm, irritable } \\
\text { bowel disease, anterior } \\
\text { resection syndrome }\end{array}$ \\
\hline
\end{tabular}

a Adapted with permission from: Andreyev et al. ${ }^{43}$ (https://creativecommons.org/licenses/by-nc/3.0/legalcode). 
and stenosis, decreased sexual interest, and dyspareunia ${ }^{49}$. Vaginal dilators can help to improve vaginal elasticity and reduce fibrosis: their use has been associated with lesser rates of self-reported vaginal stenosis ${ }^{51}$. Experts recommend starting dilation 4 weeks after RT, at a frequency of 2-3 times weekly (1-3 minutes) for 9-12 months ${ }^{52}$. Referral to a trained physiotherapist for pelvic physiotherapy and education might facilitate dilator use and progress monitoring. Vaginal morbidity should be assessed before treatment, once every 3 months for the first 2 years after treatment, and then every 6 months thereafter ${ }^{53}$. Water-based non-hormonal lubricants might help vaginal dryness during intercourse ${ }^{54}$. Sexual counselling before treatment start might be beneficial, and referral to a psychologist or sexual health specialist could be warranted if sexual concerns arise ${ }^{49,55}$.

Fertility should be explored before treatment in patients who are considering pregnancy after treatment completion. A multidisciplinary approach involving reproductive endocrinologists, gynecologists, and maternal-fetal medicine specialists is recommended ${ }^{56}$. Women who have had pelvic RT can be at increased risk for spontaneous miscarriages, preterm labor, low birth weight, and placental abnormalities ${ }^{56}$. These survivors should be closely followed by a multidisciplinary team throughout pregnancy ${ }^{56}$.

\section{SUMMARY}

Radiotherapy treatments are associated with significant side effects that can negatively affect quality of life for cancer survivors. Although newer techniques in the field of radiation oncology have helped to reduce some of the adverse effects, further extensive research is needed to minimize RT-induced deleterious outcomes. All providers caring for cancer survivors, including general practitioners in oncology, should carefully assess and provide management for RT-related effects.

\section{Key Points}

Radiation-induced side effects adversely affect quality of life for cancer survivors.

Screening and management of RT-induced early and late effects are crucial parts of the survivorship care agenda. Family physicians and general practitioners in oncology are key providers in the management of comorbid conditions, promotion of healthy lifestyles, and treatment of RT-induced side effects.

\section{CONFLICT OF INTEREST DISCLOSURES}

We have read and understood Current Oncology's policy on disclosing conflicts of interest, and we declare that we have none.

\section{AUTHOR AFFILIATIONS}

*Division of Radiation Oncology, McGill University, ${ }^{\dagger}$ Department of Family Medicine (Secondary Care), Division of Supportive and Palliative Medicine, McGill University Health Centre, and McGill University, ${ }^{\ddagger}$ Cancer Care Mission Patients’ Committee, McGill University Health Centre, and ${ }^{\S}$ Department of Oncology, Division of Radiation Oncology, Sir Mortimer B. Davis Jewish General Hospital, Montreal, QC.

\section{REFERENCES}

1. Canadian Cancer Society. Cancer Statistics at a Glance [Web page, Quebec focused]. Toronto, ON: Canadian Cancer Society; 2019. [Available at: https://www.cancer.ca/ en/cancer-information/cancer-101/cancer-statistics-at-aglance $/$ ?region $=q c$; cited 1 October 2019]

2. Lalani N, Cummings B, Halperin R, et al. The practice of radiation oncology in Canada. Int J Radiat Oncol Biol Phys 2017;97:876-80.

3. Citrin DE. Recent developments in radiotherapy. NEnglJMed 2017;377:2200-1.

4. Bentzen SM. Preventing or reducing late side effects of radiation therapy: radiobiology meets molecular pathology. Nat Rev Cancer 2006;6:702-13.

5. Chaput G, Med CP, Sussman J. Integrating primary care providers through the seasons of survivorship. Curr Oncol 2019;26:48-54.

6. Takahashi T, Hondo M, Nishimura K, et al. Evaluation of quality of life and psychological response in cancer patients treated with radiotherapy. Radiat Med 2008;26:396-401.

7. Stiegelis HE, Ranchor AV, Sanderman R. Psychological functioning in cancer patients treated with radiotherapy. Patient Educ Couns 2004;52:131-41.

8. Pitman A, Suleman S, Hyde N, Hodgkiss A. Depression and anxiety in patients with cancer. BMJ 2018;361:k1415.

9. Kawase E, Karasawa K, Shimotsu S, et al. Estimation of anxiety and depression in patients with early stage breast cancer before and after radiation therapy. Breast Cancer 2012;19:147-52.

10. Howell D, Keshavarz H, Esplen MJ, et al. on behalf of the Cancer Journey Advisory Group of the Canadian Partnership Against Cancer (CPAC). A Pan Canadian Practice Guideline: Screening, Assessment and Care of Psychosocial Distress, Depression, and Anxiety in Adults with Cancer. Toronto, ON: CPAC and the Canadian Association of Psychosocial Oncology; 2015. [Available online at: https://capo.ca/resources/ documents/guidelines/3apan- 1.pdf; cited 1 November 2019]

11. Li M, Kennedy EB, Byrne N, et al. Management of depression in patients with cancer: a clinical practice guideline. J Oncol Pract 2016;12:747-56.

12. National Comprehensive Cancer Network (NCCN). NCCNClinical Practice Guidelines in Oncology: Cancer-Related Fatigue. Ver. 1.2020. Fort Washington, PA: NCCN; 2019. [Current version available online at: https://www.nccn.org/professionals/ physician_gls/pdf/fatigue.pdf (free registration required); cited 26 October 2019]

13. Turriziani A, Mattiucci GC, Montoro C, et al. Radiotherapy-related fatigue: incidence and predictive factors. Rays 2005;30:197-203.

14. Bower JE, Ganz PA, Aziz N, Fahey JL. Fatigue and proinflammatory cytokine activity in breast cancer survivors. Psychosom Med 2002;64:604-11.

15. Juvet LK, Thune I, Elvsaas IKO, et al. The effect of exercise on fatigue and physical functioning in breast cancer patients during and after treatment and at 6 months follow-up: a meta-analysis. Breast 2017;33:166-77.

16. Ben-Josef AM, Chen J, Wileyto P, et al. Effect of Eischens yoga during radiation therapy on prostate cancer patient symptoms and quality of life: a randomized phase II trial. Int J Radiat Oncol Biol Phys 2017;98:1036-44.

17. Chakrabarty J, Vidyasagar M, Fernandes D, Joisa G, Varghese $P$, Mayya S. Effectiveness of pranayama on cancer-related fatigue in breast cancer patients undergoing radiation therapy: a randomized controlled trial. Int J Yoga 2015;8:47-53.

18. Lengacher CA, Reich RR, Paterson CL, et al. Examination of broad symptom improvement resulting from mindfulnessbased stress reduction in breast cancer survivors: a randomized controlled trial. J Clin Oncol 2016;34:2827-34. 
19. Balk J, Day R, Rosenzweig M, Beriwal S. Pilot, randomized, modified, double-blind, placebo-controlled trial of acupuncture for cancer-related fatigue. J Soc Integr Oncol 2009; 7:4-11.

20. Strojan P, Hutcheson KA, Eisbruch A, et al. Treatment of late sequelae after radiotherapy for head and neck cancer. Cancer Treat Rev 2017;59:79-92.

21. Lalla RV, Bowen J, Barasch A, et al. on behalf of the Mucositis Guidelines Leadership Group of the Multinational Association of Supportive Care in Cancer and International Society of Oral Oncology (MASCC/ISOO). MASCC/ISOO clinical practice guidelines for the management of mucositis secondary to cancer therapy. Cancer 2015;120:1453-61.

22. Tyker A, Franco J, Massa ST, Desai SC, Walen SG. Treatment for lymphedema following head and neck cancer therapy: a systematic review. Am J Otolaryngol 2019;40:761-9.

23. Colevas AD, Yom SS, Pfister DG, et al. NCCN guidelines insights: head and neck cancers, version 1.2018. J Natl Compr Canc Netw 2018;16:479-90.

24. Baharvand M, ShoalehSaadi N, Barakian R, Moghaddam EJ. Taste alteration and impact on quality of life after head and neck radiotherapy. J Oral Pathol Med 2013;42:106-12.

25. Yamashita H, Nakagawa K, Tago M, et al. Taste dysfunction in patients receiving radiotherapy. Head Neck 2006;28:508-16.

26. Sandow PL, Hejrat-Yazdi M, Heft MW. Taste loss and recovery following radiation therapy. J Dent Res 2006;85:608-11.

27. Nguyen NP, Frank C, Moltz CC, et al. Impact of dysphagia on quality of life after treatment of head-and-neck cancer. Int $J$ Radiat Oncol Biol Phys 2005;61:772-8.

28. Eisbruch A, Schwartz M, Rasch C, et al. Dysphagia and aspiration after chemoradiotherapy for head-and-neck cancer: which anatomic structures are affected and can they be spared by IMRT? Int J Radiat Oncol Biol Phys 2004;60:1425-39.

29. O'Sullivan B, Levin W. Late radiation-related fibrosis: pathogenesis, manifestations, and current management. Semin Radiat Oncol 2003;13:274-89.

30. Greco E, Simic T, Ringash J, Tomlinson G, Inamoto Y, Martino R. Dysphagia treatment for patients with head and neck cancer undergoing radiation therapy: a meta-analysis review. Int J Radiat Oncol Biol Phys 2018;101:421-44.

31. Chapuy CI, Annino DJ, Tishler RB, Haddad RI, Snavely A, Goguen LA. Success of endoscopic pharyngoesophageal dilation after head and neck cancer treatment. Laryngoscope 2013;123:3066-73.

32. Pinna R, Campus G, Cumbo E, Mura I, Milia E. Xerostomia induced by radiotherapy: an overview of the physiopathology, clinical evidence, and management of the oral damage. Ther Clin Risk Manag 2015;11:171-88.

33. Salum FG, Medella-Junior FAC, Figueiredo MAZ, Cherubini K. Salivary hypofunction: an update on therapeutic strategies. Gerodontology 2018;35:305-16.

34. Carpenter DJ, Mowery YM, Broadwater G, et al. The risk of carotid stenosis in head and neck cancer patients after radiation therapy. Oral Oncol 2018;80:9-15.

35. Hanania AN, Mainwaring, W, Ghebre YT, Hanania NA, Ludwig M. Radiation-induced lung injury: assessment and management. Chest 2019;156:150-62.

36. Giuranno L, Ient J, De Ruysscher D, Vooijs MA. Radiationinduced lung injury (RILI). Front Oncol 2019;9:877.

37. Deng G, Liang N, Xie J, et al. Pulmonary toxicity generated from radiotherapeutic treatment of thoracic malignancies. Oncol Lett 2017;14:501-11.
38. Wang H, Wei J, Zheng Q, et al. Radiation-induced heart disease: a review of classification, mechanism and prevention. Int J Biol Sci 2019;15:2128-38.

39. Lee Chuy K, Nahhas O, Dominic P, et al. Cardiovascular complications associated with mediastinal radiation. Curr Treat Options Cardiovasc Med 2019;21:31.

40. Armenian SH, Lacchetti C, Lenihan D. Prevention and monitoring of cardiac dysfunction in survivors of adult cancers: American Society of Clinical Oncology clinical practice guideline summary. J Oncol Pract 2017;13:270-5.

41. Children's Oncology Group. Long-Term Follow-Up Guidelines for Survivors of Childhood, Adolescent, and Young Adult Cancers. Monrovia, CA: Children's Oncology Group; 2018. [Available online at: http://www.survivorshipguidelines. org; cited 20 October 2019]

42. Adams E, Boulton MG, Horne A, et al. The effects of pelvic radiotherapy on cancer survivors: symptom profile, psychological morbidity and quality of life. Clin Oncol (R Coll Radiol) 2014;26:10-17.

43. Andreyev HJ, Muls AC, Norton C, et al. Guidance: the practical management of the gastrointestinal symptoms of pelvic radiation disease. Frontline Gastroenterol 2015;6:53-72.

44. Fuccio L, Frazzoni L, Guido A. Prevention of pelvic radiation disease. World J Gastrointest Pharmacol Ther 2015;6:1-9.

45. Fuccio L, Guido A, Andreyev HJ. Management of intestinal complications in patients with pelvic radiation disease. Clin Gastroenterol Hepatol 2012;10:1326-34.e4.

46. Lawrie TA, Green JT, Beresford M, et al. Interventions to reduce acute and late adverse gastrointestinal effects of pelvic radiotherapy for primary pelvic cancers. Cochrane Database Syst Rev 2018;1:CD012529.

47. Incrocci L, Jensen PT. Pelvic radiotherapy and sexual function in men and women. J Sex Med 2013;10 (suppl 1):53-64.

48. Gaither TW, Awad MA, Osterberg EC, et al. The natural history of erectile dysfunction after prostatic radiotherapy: a systematic review and meta-analysis. J Sex Med 2017;14:1071-8.

49. Berkey FJ. Managing the adverse effects of radiation therapy. Am Fam Physician 2010;82:381-8.

50. Mahmood J, Shamah AA, Creed TM, et al. Radiation-induced erectile dysfunction: recent advances and future directions. Adv Radiat Oncol 2016;1:161-9.

51. Miles T, Johnson N. Vaginal dilator therapy for women receiving pelvic radiotherapy. Cochrane Database Syst Rev 2014;9:CD007291.

52. Bakker RM, ter Kuile MM, Vermeer WM, et al. Sexual rehabilitation after pelvic radiotherapy and vaginal dilator use: consensus using the Delphi method. Int J Gynecol Cancer 2014;24:1499-506.

53. Morris L, Do V, Chard J, Brand AH. Radiation-induced vaginal stenosis: current perspectives. Int J Womens Health 2017;9:273-9.

54. Canadian Cancer Society. Sex, Intimacy and Cancer. Toronto, ON: Canadian Cancer Society; 2018.

55. National Comprehensive Cancer Network (NCCN). NCCNClinical Practice Guidelines in Oncology: Survivorship. Ver. 1.2020. Fort Washington, PA: NCCN; 2020. [Current version available online at: https://www.nccn.org/professionals/physician gls/pdf/survivorship.pdf (free registration required); cited 26 October 2019]

56. Wo JY, Viswanathan AN. Impact of radiotherapy on fertility, pregnancy, and neonatal outcomes in female cancer patients. Int J Radiat Oncol Biol Phys 2009;73:1304-12. 